\title{
İnce Dane İçeriğinin Siltli Kum Zeminlerin Drenajsız Kayma Dayanımı Davranışı ve Durağan Durum Çizgisi Üzerindeki Etkisi
}

\author{
Muhammed MAHMUDİ , Devrim ERDOĞAN \\ Ege Üniversitesi, Inşaat Mühendisliği Bölümü, İzmir, 35100, Türkiye \\ (ORCID: 0000-0002-3937-3571) (ORCID: 0000-0003-3525-9031)
}

\begin{abstract}
Öz
İnce dane içeren kum zeminlerin gerek drenajlı gerekse drenajsız yükleme koşulları altındaki kayma dayanımı davranışıları, konsolidasyon sonrası başlangıç koşulları yanısıra, ince dane içeriği, ince dane plastisitesi, iri ve ince danelerin şekli ve ortalama efektif gerilme düzeyinden etkilenmektedir. Dolayısı ile ince dane içeren zeminlerin davranışlarının değerlendirilmesi için temiz kuma göre daha fazla parametre ele alınmalıdır. Kritik durum zemin mekaniği (CSSM), tüm bu parametreleri göz önünde bulundurarak bu zemin türlerinin davranışını anlamak için uygun bir çerçevedir. Bu çalışmada $\% 10, \% 20 ; \% 30, \% 40$ ve $\% 50$ oranlarında düşük plastisiteli silt içeren kum-silt karışımı örnekleri üzerinde $50 \mathrm{kPa}, 100 \mathrm{kPa}$ ve $200 \mathrm{kPa}$ efektif konsolidasiyon basınçları altına bir dizi konsolidasyonlu drenajsız statik üç eksenli basınç deneyi gerçekleştirilmiştir. Deneysel sonuçlar, örneklerin drenajsız kayma dayanımı davranışlanının ve durağan durum çizgisinin (SSL) ince dane içeriğinden önemli ölçüde etkilendiğini göstermektedir. Belirli bir eşik ince dane içeriğine kadar durağan durum çizgisi (SSL) konumunun temiz kum konumundan aşağıya doğru hareket ettiği ve bu değerin ötesinde, ince içeriğin artmasıyla yukarı doğru hareket ettiği görülmüştür. Bu da ince dane içeriğinin değişimi ile birlikte örneklerin drenajsız kayma dayanımı davranışının ve sıkışma eğiliminin değiştiğini göstermektedir. Bununla birlikte durağan durum parametre $\left(\mathrm{M}_{\mathrm{ss}}\right)$ ve durağan durumundaki mobilize sürtünme açısı $\left(\varphi_{\mathrm{ss}}\right)$ değerlerinin de ince dane içeriğinden etkilendiği görülmüştür.
\end{abstract}

Anahtar kelimeler: Drenajsız Kayma Dayanımı, Durağan Durum, Durağan Durum Parametresi.

\section{The Effect of Fine Content on Undrained Shear Strength Behavior and Steady State Line of Silty Sand Soils}

\begin{abstract}
Shear strength behavior of sand soils with fines under both drained and undrained loading conditions is affected by the initial conditions after consolidation as well as the fine grain content, fine grain plasticity, coarse and fine grain shapes and mean effective stress level. Therefore, in order to evaluate the behavior of soils containing fine grain, more parameters should be considered compared to clean sand. Critical state soil mechanics (CSSM) is an appropriate framework to understand the behavior of this soil types with considering all of the effective parameters. In this study a series of consolidated undrained static triaxial tests were carried out on sand-silt mixtures containing $10 \%, 20 \%, 30 \%$, $40 \%$ and $50 \%$ low plasticity silt at an effective consolidation pressures of $50 \mathrm{kPa}, 100 \mathrm{kPa}$ and $200 \mathrm{kPa}$. The experimental results show that undrained shear strength behavior and steady state line (SSL) are significantly affected by the fine grain contents. It was observed that up to a threshold fine content the location of the SSL moves downward from the clean sand position and beyond that, it move upward with the increase of the fine content. This shows that undrained shear strength behavior and compression tendency of the samples change with the change of the fine grain content. However, it was observed that the steady state parameter $\left(M_{s s}\right)$ and the mobilized friction angle $\left(\varphi_{s s}\right)$ values in steady state were also affected by the fines content.
\end{abstract}

Keywords: Undrained shear strength, Steady State, Steady State parameter.

\section{Giriş}

İzotropik olarak konsolide edilmiş temiz kum örnekleri üzerinde yapılan konsolidasyonlu drenajsız statik üç eksenli basınç deneylerine göre, temiz kum, drenajsız koşullar altında, akma (Flow), sınırlı akma (Limited Flow) ve sertleşme (Non-Flow) şeklinde tipik olarak üç farklı gerilme-deformasyon

"Sorumlu yazar: mu.mahmudi@hotmail.com

Geliş Tarihi: 08.01.2021, Kabul Tarihi: 21.04.2021 
davranışı sergilemektedir [1-4]. Bu davranış tiplerinin konsolidasyon aşaması sonunda yani kesme aşaması öncesindeki başlangıç durum parametrelerine (başlangıç boşluk oranı $\left(\mathrm{e}_{0}\right)$, efektif konsolidasyon basıncı $\left(\mathrm{p}_{0}^{\prime}\right)$ ve başlangıç deviatör gerilmeler $\left(\mathrm{q}_{0}^{\prime}\right)$ ) önemli ölçüde bağlı olduğu, literatürdeki deneysel çalışmalarda açık bir şekilde ortaya konmuştur [3, 5-13].

Ancak, ince dane içeren kum zeminlerin drenajsız koşullardaki kayma dayanımı davranışı, konsolidasyon sonrası başlangıç durum parametrelerinin dışında, ince dane içeriği, kil/silt oranı, ince dane plastisitesi, ince ve iri dane şekli gibi parametrelerden de etkilenmektedir. Bu parametrelerden, ince dane içeriğinin etkisini içeren literatüre bakıldığında, bazı çalışmalarda ince dane içeriğinin artması ile birlikte örneklerin kayma dayanımının sürekli olarak azaldığ 1 , bazılarında ise sürekli olarak arttığı gözlenmiştir. Diğer taraftan son yıllarda yapılan çalışmalarda [14-29], ortaya çıkan üçüncü bulgu ince dane içeriğinin eşik ince dane içeriğine (Threshold Fine Content, $f c_{t h}$ ) kadar artması ile birlikte kayma dayanımının azaldığı ve bu eşik değerinden daha yüksek ince dane içeriklerinde ise yeniden artış meydana geldiği gözlenmiştir. Dolayısı ile ince dane içeren kum zeminlerin davranışını incelerken, temiz kuma göre daha fazla parametre göz önüne alınarak değerlendirilme yapılması gerekmektedir.

Yükleme sırasında numune içerisinde gelişen gerilme, deformasyon, hacimsel değişim eğilimleri ve ortalama efektif gerilme düzeyi arasındaki ilişkiyi sistematik bir şekilde kurma kapasitesine sahip olan Kritik Durum Zemin Mekaniği (CSSM), sözü geçen tüm parametreleri göz önünde bulundurarak davranışı anlamlandırmak için güçlü bir çerçevedir. Literatüre bakıldığında, bu teorinin çoğu araştırmacı [5, 26, 29, 30-42] tarafından temiz kum ve ince dane içeren kumların statik ve dinamik yükleme koşulları altındaki davranışlarının yorumlanması için yoğun bir şekilde kullanıldığı görülmektedir.

Kritik durum zemin mekaniği çerçevesinde ince danelerin kum zeminlerin drenajsız kayma dayanımı davranışları üzerindeki etkisi en çok durağan durum çizgisinin değişimi ile ele alınabilmektedir. Ancak yapılan çalışmalarda, durağan durum çizgisinin değişimi ile ilgili farklı bulgular bulunmaktadır. Literatürde, bu farklı davranışların başlıca nedenleri; farklı başlangıç koşullari (boşluk oranı, rölatif sıkılık, efektif konsolidasyon basınc1), örnek hazırlama yöntemi ve örneklerin konsolidasyon geçmişi olarak ifade edilmektedir [16, 43-51]. Bu çalışmada, ince dane içeriğinin, doğada çok yaygın olarak bulunabilen suya doygun siltli kumların drenajsız kayma dayanımı davranışları üzerindeki etkisi, durağan durum çizgisi ve durağan durum parametresinin değişimi ile birlikte incelenmiştir ve literatürdeki deneysel bulgular ile karşılaş̧ırılmıştır.

\subsection{Durağan Durum ve Durağan Durum Çizgisi}

İnce dane içeren kum zeminlerin drenajsız kayma dayanımı davranışı sadece ince dane içeriğine bağlı olmayıp bunun yanı sıra boşluk oranı değişimi ve ortalama efektif gerilme düzeyinden de önemli ölçüde etkilenmektedir. Kritik durum zemin mekaniği, bu tür zeminlerin yükleme altında kayma dayanımı ve hacim değişimi davranışlarını ve mühendislik özelliklerini açılamak için uyumlu ve güçlü bir teori olarak kabul edilmektedir. Kritik durum teorisi, zeminin kayma dayanımının gerilme geçmişinden ve drenaj koşullarından bağımsız olarak yalnız boşluk oranı ve efektif gerilmelerin bir fonksiyonu olarak ifade edilebileceği varsayıma dayanmaktadır. Schofield ve Wroth [53] ile Atkinson ve Bransby [52] çalışmaları ile son hale gelen kritik durum teorisi, esas olarak üç eksenli deneylerden elde edilen sonuçlarla geliştirilmiştir. Bu anlamda, kritik durum zemin mekaniğinde, zemin davranışını modelleyebilmek için üç farklı durum parametresi kullanılmaktadır. Zeminin izotropik olduğu varsayımıyla, makroskopik bir bakış açısına dayanan orijinal ve standart kritik durum değişkenleri; ortalama efektif gerilme (p'), deviatorik gerilme (q) ve özgül hacim (v) olarak tanımlanmaktadır.

Genel gerilme koşullarında, p' ve q parametrelerini, asal gerilmeler cinsinden aşağıdaki gibi tanımlamak mümkündür. Ancak, üç eksenli basınç deneyi koşullarında (Şekil 1) bu parametreler aşağıdaki formu almaktadır.

$$
\begin{aligned}
& p^{\prime}=\frac{\sigma_{1}^{\prime}+2 \sigma_{3}^{\prime}}{3} ; \sigma_{1}>\sigma_{3} \\
& q=\sigma_{1}^{\prime}-\sigma_{3}^{\prime}=\sigma_{1}-\sigma_{3} \\
& v=1+e
\end{aligned}
$$



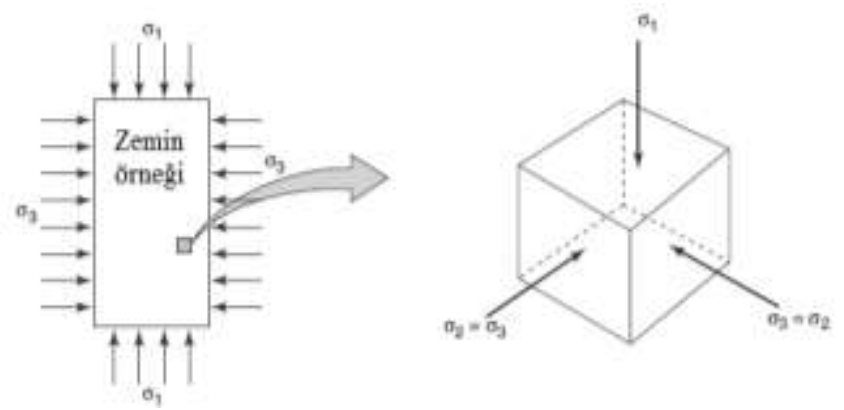

Şekil 1. Üç eksenli basınç deneyi, normal gerilme durumu

Şekil 2'de gösterildiği gibi, p'-q-v üç boyutlu uzayında bir zeminin maruz kalabileceği tüm gerilme koşullarını kapsayan idealize bir sınır durum yüzeyi (State Boundary Surface) bulunmaktadır. Görüldüğü üzere, sınır durum yüzeyi; Roscoe yüzeyi, Hvorslev yüzeyi ve çekme bölgesi yüzeyleri olarak adlandırılan üç ayrı sınır durum yüzeyinden oluşmaktadır. Böylece, bir zemin için sınır durum yüzeyi, normal konsolidasyon çizgisi (NCL), kritik durum çizgisi (CSL), çekme bölgesi çizgisi ve boşluk oranı aksları arasında sınırlanmaktadır. Dolayısıyla drenajsız koşullar altında bir zemin örneğinin davranışını yorumlayabilmek için kritik durum, kritik durum çizgisi (CSL) ve bu durum için tanımlanan kritik durum parametrelerinin tanımlanması önemlidir

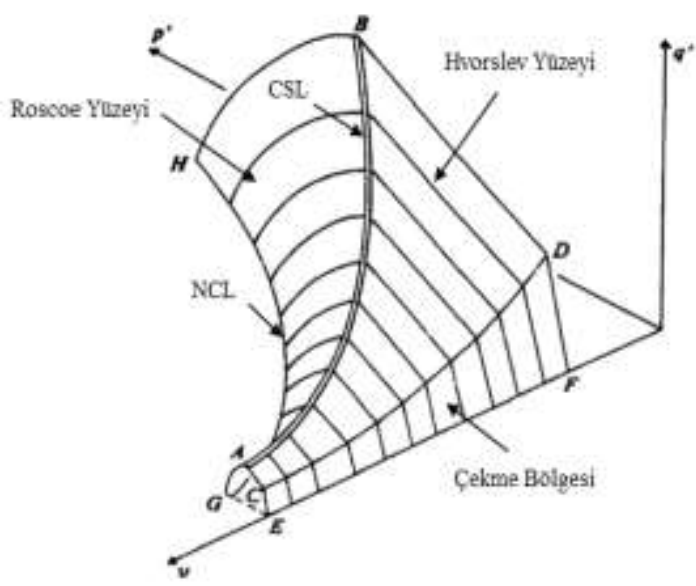

Şekil 2. Tamamlanan sınırdurum yüzeyleri durumları (Atkinson and Barasby, [52])

Kritik durum (Critical State, CS) ifadesi zeminlerin davranışını modellemek için ana terimlerden birisi olup, ilk olarak Roscoe ve ark. [54], tarafindan "zeminin sabit boşluk oranında ve sabit gerilmeler altında deformasyona devam etmesi” olarak tanımlamıştır. Kritik durum matematiksel olarak aşağıda yazılan formda ifade edilebilir. Literatürde benzer tanımlamalar ise bulunmaktadır $[24,55]$.

$d_{q}=0, \quad d_{p^{\prime}}=0, \quad d \varepsilon_{v}=0$, iken $\left|d \varepsilon_{q}\right| \neq 0$

$\varepsilon_{v}$ : Hacimsel birim deformasyon

$\varepsilon_{\mathrm{q}}:$ Deviatorik birim deformasyon

$\mathrm{p}^{\prime}$ : Ortalama efektif gerilme

$\mathrm{q}$ : Deviatorik gerilme (kayma gerilmesi)

Daha sonra Poulos [56], sabit kayma gerilmesi ve sabit efektif çevre basıncı altında, sabit hacim (drenajlı durumda), sabit hacim değişimi eğilimi (drenajsız durum) ve sabit hızdaki akışı (sürekli deformasyonaların meydana gelmesi) durumunu durağan durumu (Steady State, SS) olarak tanımlanmıştır. Bu ifade ise matematiksel olarak aşağıda yazılan formda tanımlanabilir. Burada, "du" boşluk suyu basıncı değişimidir.

$$
d_{q}=0, \quad d_{p^{\prime}}=0, \quad d \varepsilon_{v}=0, \quad d u=0 \text { iken }\left|d \varepsilon_{q}\right| \neq 0
$$


Görüldüğü üzere, teorik ve matematiksel formülasyon olarak kritik durum (CS) ve durağan durum (SS) arasında bir fark yoktur. Literatürdeki deneysel çalışmalar incelendiğinde, CS ve SS durumları arasında bu durumun elde ediliş yöntemleri dışında teorik olarak bir farkın olmadığı sonucuna varılabilir [28, 57-59]. Bununla birlikte, deneysel çalışmalarda kritik duruma drenejlı deneylerden ve durağan duruma ise drenajsız deneylerden ulaşilabileceği ifade edilmektedir. Drenajsız üç eksenli basınç deneylerinde, deviatorik kayma birim deformasyonun sabit durumunda boşluk oranı ile efektif çevre basınc i ilişkisini tanımlayan noktaların yeri Durağan Durum Çizgisi (Steady State Line, SSL) olarak adlandırılmaktadır. Şekil 3'te durağan durum çizgisi ve bu çizginin $v$-p' ve p'-q düzlemlerine indirgenmiş hali görülmektedir. Drenajsız koşullarda zemin örneğinin başlangıç boşluk oranı, efektif konsolidasyon basıncı ne olursa olsun kesme sırasında ulaşılmak istenen hedef her zaman için durağan durum çizgisidir (SSL). Ancak örneğin sıkılık durumuna göre SSL çizgisine sağdan veya soldan yaklaşma eğilimi meydana gelecektir. Dolayısıyla başlangıç durumu durağan durum çizgisi üstünde kalan örneklerde akma veya sınırlı akma davranışı ve başlangıç durumu durağan durum çizgisi altında kalan örnekler için genişleme ve sertleşme davranışı beklenmektedir.

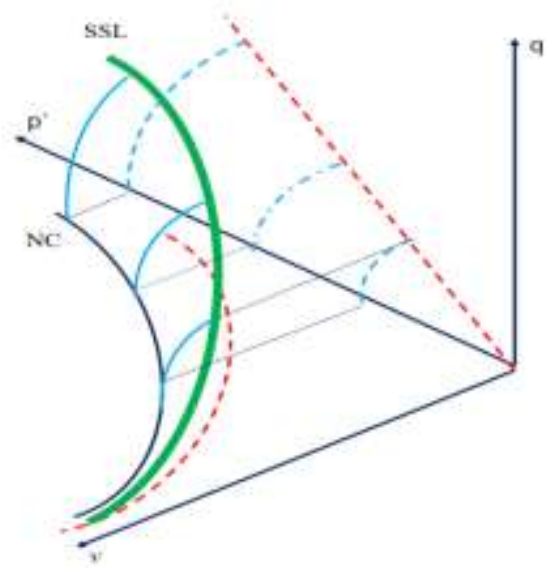

Şekil 3. v-p'-q uzayında durağan durum çizgisinin gösterilmesi

\section{Materyal ve Metot}

$\mathrm{Bu}$ çalışmada, kum-silt karışımlarının iri dane matrisini temsil etmek üzere Gölmarmara kumu, ince dane matrisini temsil etmek üzere Aydın ili, Söke ilçesi'nden temin edilen doğal silt malzemesi tercih edilmiştir. Kum ve silt malzemelerine ait fiziksel ve indeks özelliklerinin belirlenmesi amaciyla bu malzemeler üzerinde hidrometre (ASTM D7928, [60]), özgül ağırlık ve Atterberg limit deneyleri (ASTM D4318, [61]) gerçekleştirilmiştir. Likit limit deneyleri düşen koni deneyleri ile elde edilmiştir. Kum (S) ve silt (M) örnekleri için elek analizi ve hidrometre deney sonuçlarından elde edilen dane çapı dağılımı Şekil 4'te görülmektedir. Ayrıca bu örneklere ait fiziksel özellikler, indeks özellikleri ve zemin sinıfları Tablo 1'de verilmiştir. Şekil 4'deki dane çapı dağılım eğrilerine göre Gölmarmara kumunun zemin sınıfı, Birleştirilmiş Zemin Sınıflandırma Sistemi'ne (USCS) göre kötü derecelenmiş temiz kumdur (SP) ve Amerikan Karayolları (AASHTO) sinıflandırma sisteminde A-1-b grubunda yer almaktadır. Kum malzemesinin No 200 elek altında kalan ince dane kısımı her ne kadar az olsa da karışım örneklerinde ince dane oranını etkilememek amacıyla kullanılmamıştır. Doğal silt malzemesinin USCS'e göre zemin sınıfı düşük plastisiteli silttir (ML). Bu çalışmada, \%10, \%20, \%30, \%40 ve \%50 oranlarında silt içeren kum (S)-silt (M) karışımları üzerinde farklı efektif konsolidasyon basınçları (50, 100 ve $200 \mathrm{kPa}$ ) altında konsolidasyonlu drenajsız statik üç eksenli basınç deneyleri gerçekleştirilmiştir. İnce dane içeriği ile birlikte örneklerin rölatif sıkılığı etkisini de inceleyebilmek amacıyla hazırlanan tüm karışımlar gevşek $(\mathrm{Dr}=\% 25)$ ve sıkı $(\mathrm{Dr}=\% 75)$ rölatif sıkılıklarda deneylere tabi tutulmuştur. 


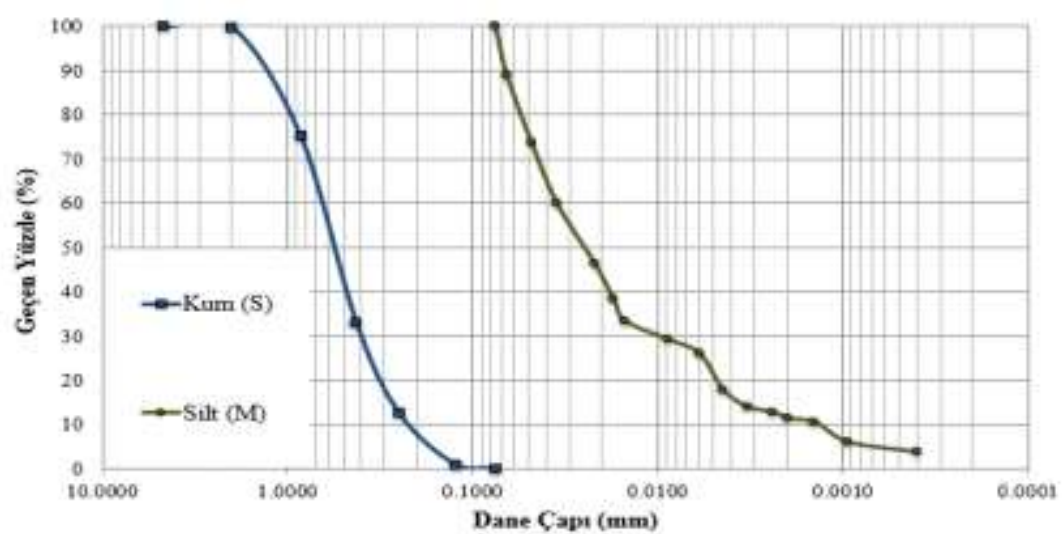

Şekil 4. Deneylerde kullanılan kum ve silt malzemelerine ait dane çapı dağılımı

Tablo 1. Fiziksel ve indeks özellikler

\begin{tabular}{lccccccc}
\hline \multicolumn{1}{c}{ Zemin Parametresi } & Kum (S) & Silt (M) & 90S-10M & $80 S-20 \mathrm{M}$ & $70 \mathrm{~S}-30 \mathrm{M}$ & 60S-40M & $50 \mathrm{~S}-50 \mathrm{M}$ \\
\hline Likit Limit, LL (\%) & - & 35 & - & - & - & - & - \\
Plastik Limit, PL (\%) & - & 31 & - & - & - & - & - \\
Plastisite İndisi, PI (\%) & $\mathrm{NP}$ & 4 & $\mathrm{NP}$ & $\mathrm{NP}$ & $\mathrm{NP}$ & $\mathrm{NP}$ & $\mathrm{NP}$ \\
Zemin Sinifi & $\mathrm{SP}$ & $\mathrm{ML}$ & $\mathrm{SW}-\mathrm{SM}$ & $\mathrm{SM}$ & $\mathrm{SM}$ & $\mathrm{SM}$ & $\mathrm{ML}$ \\
$\mathrm{e}_{\text {maks }}$ & 0.810 & 1.446 & 0.76 & 0.723 & 0.70 & 0.707 & 0.816 \\
$\mathrm{e}_{\text {min }}$ & 0.524 & 0.986 & 0.464 & 0.422 & 0.409 & 0.428 & 0.536 \\
$-\mathrm{No} \mathrm{200} \mathrm{( \% )}$ & 0 & 100 & 10 & 20 & 30 & 40 & 50 \\
$\mathrm{Cu}$ & 2.89 & 4.20 & 8.00 & 7.33 & 6.53 & 5.47 & 4.00 \\
$\mathrm{Cc}$ & 1.09 & - & 2.42 & 1.40 & 0.15 & 0.18 & 0.25 \\
$\mathrm{G}_{\mathrm{s}}$ & 2.65 & 2.68 & 2.654 & 2.657 & 2.659 & 2.662 & 2.667 \\
\hline
\end{tabular}

İri ve ince danelerden oluşan bir zemin karışımının mekanik davranışı danelerin dizilişi (doku) ve danelerin birbirine kenetlenmesi açısından önemli ölçüde etkilenmektedir [62]. Dolayısıyla bir zemin örneğinde iri ve ince dane matrislerini oluşturan malzemelerin mikro yapı analizleri deney sonuçlarının yorumlanması açısından faydalıdır. Şekil 5a ve Şekil 5b'de temiz kum ve saf silt için alınan Taramalı Elektron Mikroskobu (SEM) analizleri verilmektedir. Burada alınan görüntülerden kum daneleri yarı köşeli (SA) ve yarı yuvarlak (SR), silt danelerinin ise keskin ve açısal şekilde olduğu görülebilmektedir.
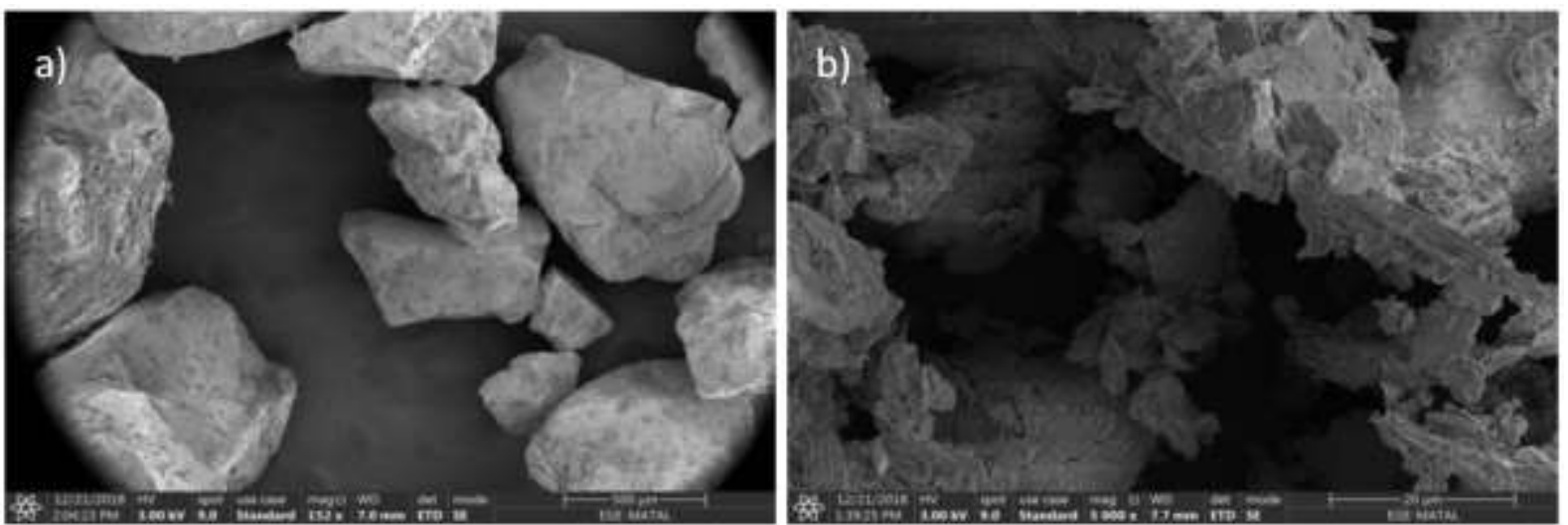

Şekil 5. SEM analizleri, a) Temiz kum, b) Silt malzemesi

Zeminlerin kayma dayanımı davranışlarının kritik durum zemin mekaniği çerçevesinde yorumlanması anlamında örneklerin yapısı ve homojenliği daha da önem kazanmaktadır [28]. Literatürde temiz kumlar için kuru yağmurlama (Dry Pluviation, DP), suda çökeltme (Water Sedimentation, WS), Bulamaç çökeli (Slurry Deposition, SD) gibi örnek hazırlama yöntemleri tercih 
edilmektedir. Ancak çoğu araştırmacı [1, 10, 11, 62-70] tarafından ince dane içeren kum zeminler için nemli (1slak) tokmaklama (Moist Tamping, MT) yöntemi tercih edilmektedir. Bunun nedeni ise bu çerçevede yapılan çalışmalarda boşluk oranı değerinin önemli olduğu ve MT yöntemi ile laboratuvarda istenilen boşluk oranı (sıkılık) değerlerine kolayca ulaşılmasıdır. Bu çalışmada da örnekler MT yöntemine göre hazırlanmıştır ve örnek boyunca daha homojen bir sıkılığın elde edilmesi için Ladd [71], tarafından önerilen detaylar dikkate alınmıştır. Deney örneklerini suya doygun hale getirebilmek için örnekler üzerinde sırasıyla karbondioksit $\left(\mathrm{CO}_{2}\right)$ geçirme, su geçirme ve geri basınç uygulama (Back Pressure) aşamaları gerçekteştirilmiştir. Deney örneği suya doygun hale getirildikten sonra geri basınç değerine göre hücre basıncının arttırılması veya azaltılması ile istenilen efektif konsolidasyon basıncına ulaşılmıştır. Konsolidasyon sonrası drenajsız yükleme hızı $1 \mathrm{~mm} /$ dak olarak seçilmiştir. Bu hız, yük uygulama sırasında boşluk suyu basıncı değişiminin kayda alınabilmesi için yeterli görülmüştür.

\section{Bulgular ve Tartışma}

\section{1. İnce Dane İçeriğinin Drenajsız Kayma Dayanımı Davranışı Üzerindeki Etkisi}

Gevşek ve sıkı sıkılıkta hazırlanan kum-silt karışım örnekleri için konsolidasyonlu drenajsız (CU) üç eksenli basınç deneyleri yükleme sırasında gözlenen efektif gerilme izleri Cambridge sistemine göre p'q düzleminde Şekil 6(a)-(f)'de verilmektedir. Bu düzlemlerde, düşey eksen deviatorik gerilme (q) değerini ve yatay eksen ortalama efektif gerilme ( $\left.\mathrm{p}^{\prime}\right)$ değerini göstermektedir. Bu grafiklerden, temiz kum ve karışım örnekler için yükleme sırasında, boşluk suyu basıncının değişimi ile değişen efektif gerilme düzeyleri ve örneklerde kayma dayanımı değişimi izlenmektedir.

Gevşek durumda, 50, 100 ve $200 \mathrm{kPa}$ efektif konsolidasyon basınçları altında silt içeriğinin değişimi ile birlikte, temiz kum ve $f c=\% 10, \% 20$ ve \%30 silt içeren örneklerde ortalama efektif gerilme değerinin konsolidasyon sonrası başlangıç değerine göre sürekli azaldığı ve kayma dayanımının da bir pik dayanım değerine kadar arttığı ve daha sonra durağan durum noktasına kadar akma tipi bir davranışın sergilendiği görülmektedir. Burada, aşırı boşluk suyu basıncının konsolidasyon sonrası başlangıç ortalama efektif gerilme seviyelerine ulaşması ile kayma dayanımlarında önemli oranda azalmalar meydana gelmektedir. Bu da statik sıvılaşma davranışı riskini oluşturmaktadır. $f c=\% 40$ ve $\% 50$ silt içeriğinde ise benzer davranış görülmektedir. Ancak, belirli bir efektif gerilme değeri sonrası aşırı boşluk suyu basıncının azalması ve otalama efektif gerilme değerinin bir miktar artması ile birlikte örneklerin tekrardan dayanım kazandığ 1 ve sınırlı akma türünde bir darvanış sergiledikleri görülmektedir. Bu davranışa göre, ince dane matrisi, kayma dayanımı kontrolünü bir geçiş ince dane içerikleriğinde ele geçirmeye başlamaktadır. Benzer davranış tiplerine literatürdeki deneysel çalışmalarda da rastlanmaktadır [64, 72-77].

Sık1 durumda, 50, 100 ve $200 \mathrm{kPa}$ efektif konsolidasyon basınçları altında silt içeriğinin değişimi ile birlikte, temiz kum ve $f c=\% 10, \% 20$ ve \%30 silt içeren örneklerde, ortalama efektif gerilme değeri konsolidasyon sonrası başlangıç değerine göre bir miktar azaldığı ve daha sonra sürekli arttığ görülmektedir. Bu örneklerde, başlangıçta çok az bir miktar sıkışma eğilimi (Contractive Tendency) görülmüştür. Ancak, artan deformasyon ile birlikte gelişen genişleme eğilimi (Dilative Tendency) nedeni ile aşırı boşluk suyu basınçlarında meydana gelen azalma ortalama efektif gerilmelerde artı̧̧ yaratmakta, buna bağlı olarak deviatör geilmeler de artmaktadır. Başka bir deyişle, bu örnek q- $\varepsilon$ düzleminde sertleşme gerilme-deformasyon davranışı göstermiştir. $f c=\% 40$ ve $\% 50$ silt içeren örnekler de benzer davranış sergilemektedir ancak bu örneklerde önce bir miktar sıkışma ve daha sonra sertleşme eğilimi gözlenmiştir. Ancak bu sertleşme eğilimi $f c=\% 10, \% 20$ ve $\% 30$ karışımlarına göre daha düşük seviyelerdedir. Bunun sebebi ise iri daneler arası boşluklarındaki ince dane içeriğinin artması ve artık hacim değişimi eğiliminin silt matrisi tarafından kontrol edilmesidir. Bu bulgular, literatürdeki sık1 durumda hazırlanmış kum-silt karışımları üzerinde yapılmış olan deneyler ile desteklenmektedir [78]. 

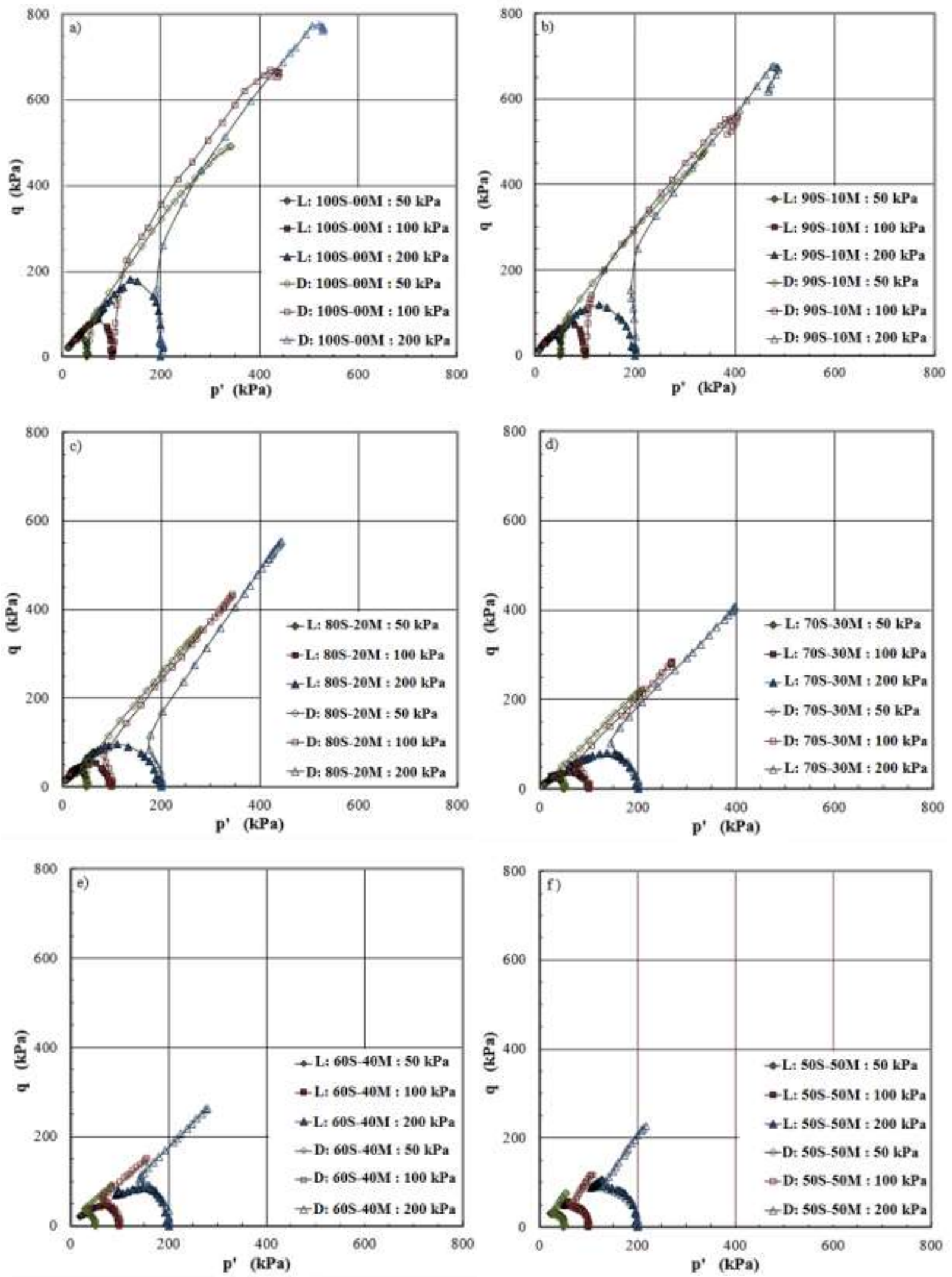

Şekil 6. p'-q düzleminde gevşek (L) ve sıkı (D) sıkılıkta hazırlanmış kum (s)-silt (M) karışımlarına ait gerilme izleri, a) $\% 0$, b) $\% 10$, c) $\% 20$, d) $\% 30$, e) $\% 40$, f) $\% 50$ silt içeriği 


\section{2. İnce Dane İçeriğinin e-log(p') Düzleminde, Durağan Durum Çizgisi (SSL) Üzerindeki Etkisi}

Gevşek ve sıkı durumlarda, temiz kum (100S-00F) ve $f c=\% 10, \% 20, \% 30, \% 40, \% 50$ silt içeren örnekler için drenajsız üç eksenli basınç deneylerinden elde edilen durağan durum çizgileri (SSL) e- $\log \left(\mathrm{p}^{\prime}\right)$ düzleminde Şekil 7'de verilmiştir. Bu düzlemde, düşey eksen konsolidasyon sonrası boşluk oranını (e) ve yatay eksen ortalama efektif gerilme ( $\mathrm{p}^{\prime}$ ) değerini göstermektedir. Bu şekiller incelendiğinde; durağan durum çizgisinin silt içeriğine duyarlı olduğu görülmektedir. Bu da örneklerin kayma dayanımı davranışının değişimi anlamına gelmektedir. Bununla birlikte, ince dane içeriğinin değişimi ile birlikte örneklerin durağan durum çizgisinin eğimi de değişmektedir. Bu da örneklerde sınır durum yüzeyinin ince dane içeriğinden etkilendiği anlamına gelmektedir. Durağan durum çizgisi, silt içeriğinin \%0 (temiz kum)'dan \%30'a kadar artışı ile birlikte, aşağıya doğru hareket etmekte, \%30'dan daha yüksek silt içeriklerinde ise yön değiştirerek yukarıya doğru hareket etmektedir. Silt içeriğinin $0 \%$ ' dan $30 \%$ 'a doğru artışı sırasında durağan durum çizgisinin aşağı doğru hareketi, gevşek durumda hazırlanmış olan kumsilt karışımlarının drenajsız kayma dayanımı kaybına ve giderek daha sıkışabilir bir eğilim kazanmasına bağlanmaktadır. Durağan durum çizgisinin yön değiştirmesi, Thevanayagam, [45], tarafından zeminin iri dane matrisi kontrolünden ince dane matrisi kontrolüne geçtiği ve dolayısı ile zemin yapısı ve dokusunun değişiminden kaynaklandığı hipotezi ile açıklanmıştır. Durağan durum çizgisinin bu yön değiştirme davranış1, literatürde silt içeren kum zeminler için desteklenmektedir [12, 14-17, 19, 21-27, 29].

Burada iri dane matrisini oluşturmak üzere seçilen kum ve ince dane matrisini oluşturmak üzere seçilen silt dikkate alındığında, temiz kuma ait SSL en üst sınırı, \%30 silt içeren karışımlara ait SSL de en alt sınırı göstermektedir. Görüldüğü üzere, durağan durum çizgisinin konumu yaklaşık \%30 silt içeriğini bir geçiş ince dane içeriği olarak ortaya koymaktadır. Bu davranışın nedenini zemini oluşturan iri ve ince dane matrislerinin birbirleri üzerindeki kontrolleri mekanizmasıdır. Şöyle ki, ince dane içeriğinin değişimi zemin dokusunun değişimine yol açmakta olup, iri dane matrisi veya ince dane matrisi hakimiyetleri altındaki davranışlar belli bir geçiş ince dane içeriğinden sonra değişmektedir. $\mathrm{Bu}$ da ince dane içeriğine bağlı olarak kum zeminlerin durağan durum çizgisinin, konsolidasyon sonrası boşluk oranlarından etkilendiği anlamına gelmektedir. Literatürde bu geçiş ince dane içeriği eşik ince dane içeriği $\left(f c=f c_{t h}\right)$ olarak tanımlanmaktadır. Bu ince dane içeriğinde zeminlerin kayma dayanımı davranışları her iki matris tarafindan kontrol edilmektedir.

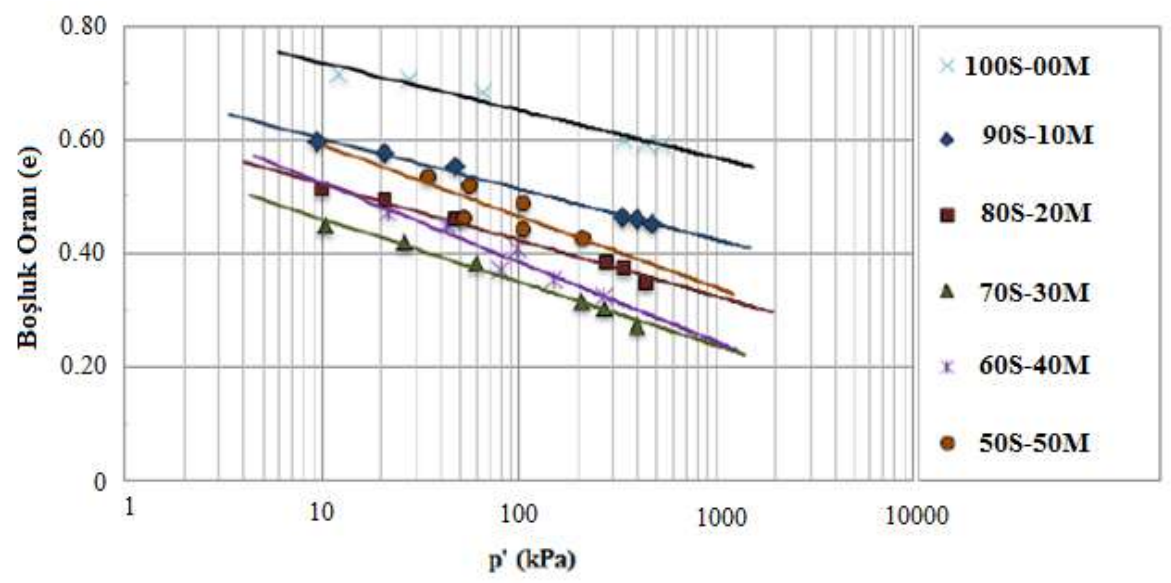

Şekil 7. e- $\log \left(\mathrm{p}^{\prime}\right)$ düzleminde kum-silt karışımlarına ait durağan durum noktaları ve durağan durumu çizgileri

\section{3. İnce Dane İçeriğinin $p^{\prime}-q$ Düzleminde, Durağan Durum Çizgisi ve Durağan Durum Parametresi Üzerindeki Etkisi}

Gevşek örnekler için $50 \mathrm{kPa}, 100 \mathrm{kPa}$ ve $200 \mathrm{kPa}$ efektif konsolidasyon basıncı altına elde edilen durağan durumu seviyeleri ve durağan durum çizgileri p'-q düzleminde verilmektedir (Şekil 8). Bu 
düzlemde ise, gevşek örneklerde durağan durum çizgisinin ince dane içeriğinden belirgin bir şekilde etkilendiği görülmektedir. $\mathrm{Bu}$ da örneklerin kayma dayanımı davranışının değişimi anlamına gelmektedir. Bununla birlikte, ince dane içeriğinin değişimi ile birlikte örneklerin durağan durum çizgisi eğiminin de değiştiği görülmektedir. Bu da örneklerde sınır durum yüzeyinin ince dane içeriğinden etkilendiği anlamına gelmektedir.

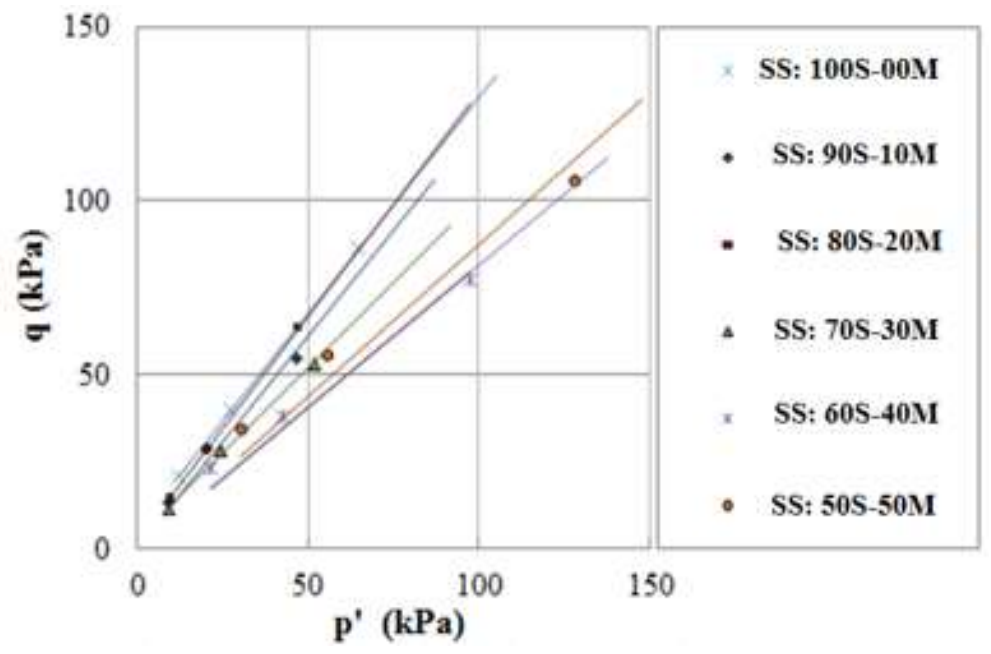

Şekil 8. Kum-silt karışım örneklerine ait durağan durum seviyeleri ve durağan durum çizgileri

Farklı efektif konsolidasyon basınçlarından elde edilen durağan durum noktalarının (sabit hacim düzlemi üzerindeki) izdüşümü eğiminin tanımlanması ile durağan durum çizgisinin eğimi $\mathrm{p}^{\prime}-\mathrm{q}$ düzleminde, $M_{\mathrm{ss}}=\mathrm{q} / \mathrm{p}^{\prime}$ denkemi ile tanımlanmaktadır. $\mathrm{Bu}$ denklemde $\mathrm{M}_{\mathrm{ss}}$, durağan durum parametresi olarak adlandırılmaktadır. Ayrıca örneklerin durağan durumunda ki içsel sürtünme açı değerleri Schofield ve Wroth [53], tarafindan tanımlanan bağlantıdan elde edilebilmektedir;

$$
\begin{aligned}
& p^{\prime}=\frac{\sigma_{1}^{\prime}+2 \sigma_{3}^{\prime}}{3} ; \sigma_{1}^{\prime}>\sigma_{3}^{\prime} \\
& q=\sigma_{1}^{\prime}-\sigma_{3}^{\prime} \\
& \sigma_{1}^{\prime}=\sigma_{3}^{\prime} \cdot\left(\frac{1+\sin \varphi_{s s}}{1-\sin \varphi_{s s}}\right) \\
& p^{\prime}=\sigma_{3}^{\prime} \cdot\left(\frac{3-\sin \varphi_{s s}}{3 \cdot\left(1-\sin \varphi_{s s}\right)}\right) \\
& q=\sigma_{3}^{\prime} \cdot\left(\frac{2 \cdot \sin \varphi_{S S}}{1-\sin \varphi_{s s}}\right) \\
& M_{s S}=\frac{q}{p^{\prime}}=\left(\frac{6 \cdot \sin \varphi_{s s}}{3-\sin \varphi_{s s}}\right)
\end{aligned}
$$

Burada;

$\mathrm{M}_{\mathrm{ss}}$ : Durağan durum çizgisinin eğimi,

$\varphi_{\text {ss: }}$ Durağan durumunda içsel sürtünme açısı, 
Kum-silt karışım örnekleri için elde edilen durağan durum parametre $\left(\mathrm{M}_{\mathrm{ss}}\right)$ ve durağan durumundaki mobilize sürtünme açısı $\left(\varphi_{\text {ss }}\right)$ değerlerinin değişimi sırasıyla Şekil $9(a)$ ve $9(b)$ 'de karşılaştırılmıştır. Bu şekillere göre; kum-silt karışım örnekleri için elde edilen $\mathbf{M}_{\mathrm{ss}}$ değerleri 1.00 ile 1.51 arasinda olup Schofield and Wroth [53] ve Atkinson and Bransby [52] tarafindan kritik durum zemin mekaniği ilkeleri ile uyum göstermektedir. Mobilize sürtünme açısı $\left(\varphi_{\text {ss }}\right)$ değerleri ise ince dane içeriğinin değişimi ile birlikte $37.20^{\circ}$ ile $23.46^{\circ}$ arasında değişmekte olup Yang ve ark. [46] tarafindan yapılan çalı̧̧madaki değerlere yakındır. Silt içeriği \%0 (temiz kum) dan \%30'a doğru yükseldikçe, $\mathrm{M}_{\mathrm{ss}}$ ve $\varphi_{\text {ss }}$ değerlerinin azaldığı görülmektedir. Ancak, silt içeriği daha da yükseldikçe, $(f c=\% 40-\% 50)$, durağan durum parametresi ve durağan durumundaki mobilize sürtünme açısı değerlerinde artış görülmektedir. Bu da örneklerde sınır durum yüzeyi alt sınırının değişimini ve duraysızlık bölgesinin de ince dane içeriğinden etkilendiği anlamına gelmektedir.
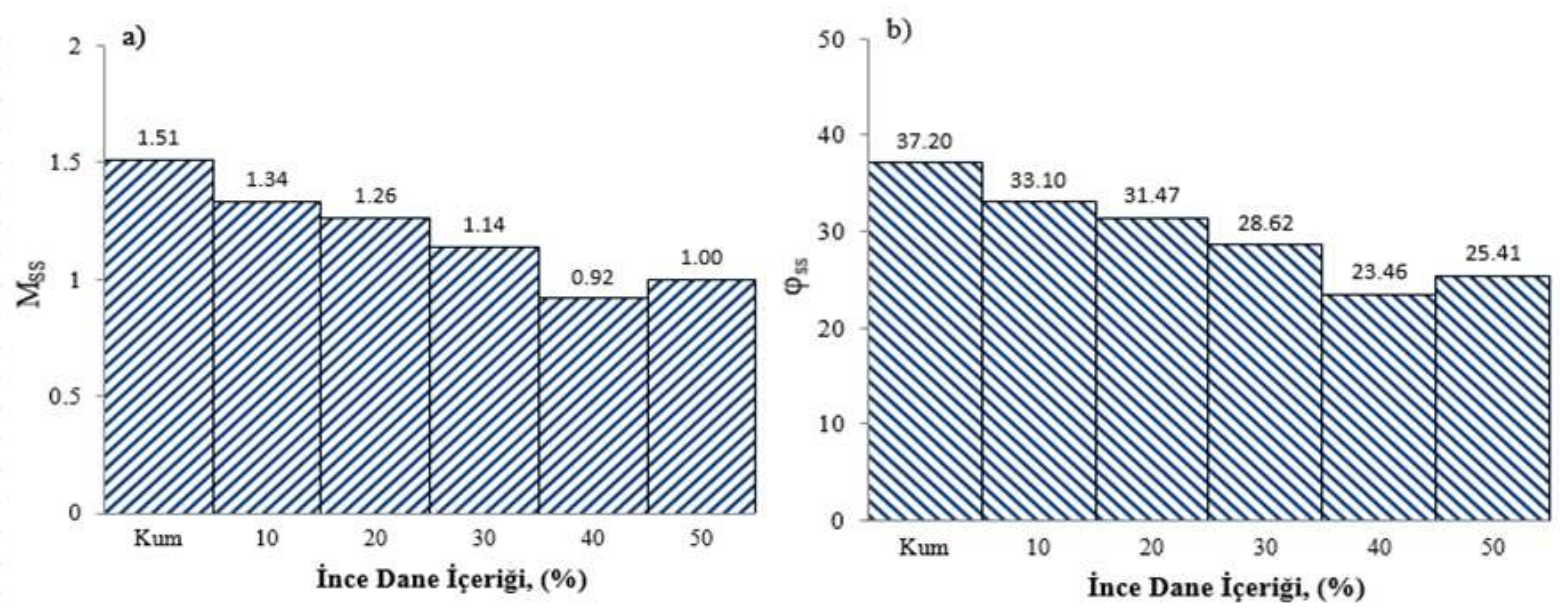

Şekil 9. Kum-silt karışım örneklerine ait, a) Durağan durum parametresi $\left(\mathrm{M}_{\mathrm{ss}}\right)$, b) Durağan durumundaki mobilize sürtünme açısı $\left(\varphi_{\text {ss }}\right)$

\section{Sonuç ve Öneriler}

$\mathrm{Bu}$ çalışmada, ince dane içeriğinin, doğada çok yaygın olarak bulunabilen suya doygun siltli kum zeminlerin drenajsız durumdaki kayma dayanımı davranışı, durağan durum çizgisi ve durağan durum parametresi üzerindeki etkisi incelenmiştir. Gevşsek durumda hazırlanan silt-kum karışımlarında, konsolidasyon sonrası başlangıç ortalama efektif gerilme düzeyine ve ince dane içeriğine bağlı olarak akma ve sınırlı akma tipinde gerilme-deformasyon davranış1 görülmüştür. Sıkı durumda ise ince dane içeriği değişimine bağlı olarak, hacimsel değişme eğilimi, önce bir miktar sıkışma ve daha sonra genişleme veya sürekli genişleme şeklinde görülmüştür. Deneysel olarak gözlemlenen bu davranışa göre, ince dane içeriğinin değişimi, zemin dokusunun değişimine yol açmakta olup, iri dane matrisi veya ince dane matrisi hâkimiyetleri altındaki davranışlar belli bir geçiş ince dane içeriğinden sonra el değiştirmektedir. $\mathrm{Bu}$ çalışmada, davranışın geçiş gösterdiği ince dane içeriği yaklaşı $f c_{t h}=\% 30$ civarında gözlenmiştir. Ayrıca, durağan durum çizgisinin (SSL) konumu da ince dane içeriğine bağlı olarak değişim göstermiştir. İnce dane içeren örneklerin durağan durum çizgisi düzeyi, temiz kumun durağan durum çizgisine göre karşılaştırıldığında, $f c_{t h}=\% 30$ 'a kadar SSL'den uzaklaşarak aşağıya doğru hareket ettiği ve $f c_{t h}>\% 30$ ince dane içeriğinde, yukarıya doğru yön değiştirdiği görülmüştür. Bu da örneklerin kayma dayanımı davranışının ve hacim değişimi eğiliminin değişimi anlamına gelmektedir. Dolayısı ile durağan durum ve durağan durum çizgisi zeminlerin kayma dayanımı davranışı ile ilişkili olup zeminlerin davranışları konusunda önemli bilgiler vermektedir. Bununla birlikte durağan durum parametre $\left(\mathrm{M}_{\mathrm{ss}}\right)$ ve durağan durumundaki mobilize sürtünme açısı $\left(\varphi_{\mathrm{ss}}\right)$ değerlerinin de ince dane içeriğinden etkilendiği görülmüsstür. 


\section{Yazarların Katkısı}

Yazarlar bu araştırma makalesine eşit katkı sunmuşlardır.

\section{Çıkar Çatışması Beyanı}

Yazarlar arasında herhangi bir çıkar çatışması bulunmamaktadır.

\section{Araştırma ve Yayın Etiği Beyanı}

Yapılan çalışmada araştırma ve yayın etiğine uyulmuştur.

\section{Kaynaklar}

[1] Castro G. 1969. Liquefaction of sands. (Doctoral dissertation), Harvard University, Cambridge, Massachusetts.

[2] Lindenberg J., Koning H.L. 1981. Critical density of sand. Geotechnique, 31 (2): 231-245.

[3] Vaid Y.P., Chung E.K.F., Kuerbis R.H. 1990. Stress path and steady state. Canadian Geotechnical Journal, 21 (1): 1-7.

[4] Sladen J.A., D'Hollander R.D., Krahn J. 1985. The liquefaction of sands, a collapse surface approach. Canadian Geotechnical Journal, 22: 564-78.

[5] Been K., Jefferies M.G. 1985. A state parameter for sands. Geotechnique, 35 (2): 99-112.

[6] Poulos S. J., Castro G., France J. 1985. Liquefaction evaluation procedure. Geotech. Engrg., 111 (6): 772-792.

[7] Mohamad R., Dobry R. 1986. Undrained monotonic and cyclic triaxial strength of sand. J. Geotech. Engrg., 112 (10): 941-958.

[8] Alarcon-Guzman A., Leonards G.A., Chameau J.L. 1988. Undrained monotonic and cyclic strength of sands. ASCE J. Geotech. Eng, 114 (10): 1089-1109.

[9] Lade P.V. 1992. Static instability and liquefaction of loose sandy slopes. Journal of Geotechnical Engineering, 118 (1): 51-71.

[10] Ishihara K. 1993. Liquefaction and flow failure during earthquakes. Geotechnique, 43 (3): 351415.

[11] Yamamuro J.A., Lade P.V. 1997. Instability of granular materials at high pressures, Soils and Foundations. Japanese Society of Soil Mechanics and Foundation Engineering, 37 (1): 41-52.

[12] Thevanayagam S., Mohan S. 2000. Intergranular state variables and stress-strain behaviour of silty sands. Geotechnique, 50 (1): 1-23.

[13] Bobei D.C., Lo S-C.R. 2001. Static liquefaction of Sydney sand mixed with both plastic and nonplastic fines. In proceedings of the 14th Southeast Asian Geotechnical Conference, 485-491.

[14] Koester J.P. 1994. The influence of fine type and content on cyclic strength. Ground Failures Under Seismic Conditions, Geotechnical Special Publication, ASCE, 44: 17-33.

[15] Koester J.P. 1998. Triggering and post-liquefaction strength issues in fine-grained soils. Physics and Mechanics of Soil Liquefaction, Ed. Lade and Yamamuro, Balkema Pubs., 77-89.

[16] Zlatovic S., Ishihara K. 1995. On the influence of nonplastic fines on resual strength. Proceedings of the 1 st International Conference on Earthquake Geotechnical Engineering, Netherlands, 23944.

[17] Thevanayagam S. 1998. Relative roles of coarse and fine grains on the mechanical response of granular mixes. ASCE, J. Geotech. \& Geoenv. Eng. in review.

[18] Thevanayagam S. 2000. Liquefaction potential and undrained fragility of silty soils. In Proceedings of the 12th World Conference on Earthquake Engineering, Auckland, New Zealand, 2383p.

[19] Polito C., Martin II J. R. 2001. Effects of nonplastic fines on the liquefaction resistance of sands. Journal of Geotechnical and Geoenvironmental Engineering, ASCE, 127 (5): 408-415.

[20] Bouckovalas G.D., Andrianopoulos K.I., Papadimitriou A.G. 2003. A critical state interpretation for the cyclic liquefaction resistance of silty sands. Soil Dynamics and Earthquake Engineering, 23: $115-125$. 
[21] Xenaki V.C., Athanasopoulos G.A. 2003. Liquefaction Resistance of Sand-Silt Mixtures: an Experimental Investigation of the Effect of Fines. Soil Dynamics and Earthquake Engineering 23: 183-194.

[22] Naeini S.A., Baziar, M.H. 2004. Effect of fines content on steady-state strength of mixed and layered samples of a sand. Soil Dynamics and Earthquake Engineering, 24: 181-187.

[23] Yang S., Lacasse S., Sandven R. 2006. Determination of the Transitional Fines Content of Mixtures of Sand and Non-plastic Fines. Geotechnical Testing Journal, 29 (2):102-107.

[24] Murthy T.G., Loukidis D., Carraro J.A.H., Prezzi M., Salgado R. 2007. Undrained Monotonic Response of Clean and Silty Sands-Non-Linear Soil Stiffness in Routine Design. Geotechnique, 57 (3): 273-288.

[25] Chiu C.F., Fu X.J. 2008. Interpreting undrained instability of mixed soils by equivalent intergranular state parameter. Géotechnique, 58 (9): 751-755.

[26] Papadopoulou A., Tika T. 2008. The effect of fine on critical state and liquefaction resistance characteristics of non-plastic silty sands. Soil and Foundations, 48 (5): 713-725.

[27] Rees S.D. 2010. Effects of Fines on the Undrained Behavior of Christchurch Sandy Soils. Ph.D. thesis, University of Canterbury, New Zealand.

[28] Rahman M.M. 2009. Modelling the influence of fines on liquefaction behaviour. Ph.D. thesis, University of New South Wales at Australian Defence Force Academy.

[29] Phan T.A.V., Hsiao D.H., Nguyen P. 2016. Critical State Line and State Parameter of Sand-Fines Mixtures. Procedia Engineering, 142: 299-306.

[30] Jovicic V., Coop M.R. 1997. Stiffness of coarse grained soils at small strains. Geotechnique, 47 (3): 545-561.

[31] Been K., Jefferies M. 2004. Stress-dilatancy in very loose sand. Canadian Geotechnical Journal, 41 (5): 972-989.

[32] Yang S.L., Sandven R., Grande L. 2006b. Instability of sand-silt mixtures. Soil Dyn Earthq Eng., 26 (2): 183-190.

[33] Wood F.M., Yamamuro J.A., Lade, P.V. 2008. Effect of depositional method on the undrained response of silty sand. Canadian Geotechnical Journal, 45: 1525-1537.

[34] Bobei D.C., Lo S.R., Wanatowski D., Gnanendran C.T., Rahman M.M. 2009. Modified state parameter for characterizing static liquefaction of sand with fines. Canadian Geotechnical Journal, 46 (3): 281-295.

[35] Abedi M., Yasrobi S. 2010. Effects of plastic fines on the instability of sand. Soil Dynamics and Earthquake Engineering, 30 (3): 61-67.

[36] Rahman M. M., Lo S.R., Cubrinovski M. 2010. On Equivalent Granular Void Rtio and Behaviour of Loose Sand. Canadian Geotechnical Journal, 45 (10): 1439-1456.

[37] Stamatopoulos C. 2010. An experimental study of the liquefaction strength of silty sands in terms of the state parameter. Soil Dynamics and Earthquake Engineering, 30: 662-678.

[38] Huang A.B., Chuang S.Y. 2011. Correlating cyclic strength with fines contents through state parameters. Soils Found, 51 (6): 991-1001.

[39] Rahman M.M., Lo S. 2011. Predicting the onset of static liquefaction of loose sand with fines, Journal of Geotechnical and Geoenvironmental Engineering, 138 (8): 1037-1041.

[40] Baki M.A.L., Rahman M.M., Lo S.R., Gnanendran C.T. 2012. Linkage between static and cyclic liquefaction of loose sand with a range of fines contents. Canadian Geotechnical Journal, 49 (8): 891-906.

[41] Qadimi A., Mohammadi A. 2014. Evaluation of state indices in predicting the cyclic and monotonic strength of sands with different fines contents. Soil Dyn Earthq Eng., 66: 443-58.

[42] Cherif Taiba A., Mahmoudi Y., Belkhatir M., Kadri A., Schanz T. 2018. Experimental characterization of the undrained instability and steady state of silty sand soils under monotonic loading conditions. International Journal of Geotechnical Engineering, 12 (5): 513-529.

[43] Høeg K., Dyvik R., Sandbækken G. 2000. Strength of Undisturbed Versus Reconstituted Silt and Silty Sand Specimens. J. Geotech. Geoenviron. Eng., 126 (7): 606-617.

[45] Vaid Y.P., Sivathayalan S. 2000. Fundamental factors affecting lique- faction susceptibility of sands. Can. Geotech. J., 37 (3): 592-606.

[46] Yang S.L., Sandven R., Grande L. 2006c. Steady-state Lines of Sand-siltmixtures. Can. Geotech. J., 43 (11): 1213-1219. 
[47] Rahman M.M., Lo S.R. 2007. Equivalent granular void ratio and state parameters for loose clean sand with small amount of fines. 10Th Australia New Zealand Conference on Geomechanics, Brisbane, Australia, 674-679.

[48] Wood F.M., Yamamuro J.A., Lade P.V. 2008. Effect of depositional method on the undrained response of silty sand. Canadian Geotechnical Journal, 45: 1525-1537.

[49] Yamamuro J.A., Wood F.M., Lade P.V. 2008. Effect of depositional method on the microstructure of silty sand. Can. Geotech. J., 45: 1538- 1555.

[50] Kwa K.A., Airey D.W. 2016. Critical state interpreation of effects of fine in silty sands. ICE Publishing, Geotechnique Latters, 6: 100-1005.

[51] Talamkhani S., Naeini S.A. 2018. International Effect of Plastic Fines on Undrained Behavior of Clayey Sands. International Journal of Geotechnical and Geological Engineering, 12 (8): 525528.

[52] Atkinson J.H., Bransby P.L. 1978. The Mechanics of Soil: An Introduction to Critical State Soil Mechanics. McGraw-Hill Book Company (UK) Limited, Maidenhead, Berkshire, England, ISBN 070841357.

[53] Schofield A.B., Wroth C.P. 1968. Critical state soil mechanics. London, McGraw-Hill.

[54] Roscoe K.H., Schofield A.N. 1958. Wroth CP. On the yielding of soils. Géotechnique, 8 (1): 22 53.

[55] Yamamuro J.A., Lade P.V. 1998. Steady-state concepts and static liquefaction of silty sands. Journal of geotechnical and geoenvironmental engineering, 124 (9): 868-877.

[56] Poulos S.J. 1981. The steady state of deformation. Journal of the Geotechnical Engineering Division, ASCE, 107 (5): 553-562.

[57] Chu J., Lo S.C.R., Lee I.K. 1993. Instability of granular soils under strain path testing. Journal of Geotechnical Engineering, 119 (5): 874-892.

[58] Bobei D.C., Lo S.R. 2001. Static liquefaction of Sydney sand mixed with both plastic and nonplastic fines. In Proceedings of the 14th Southeast Asian Geotechnical Conference, Hong Kong, 9-14.

[59] Bobei D.C., Lo S.R. 2005. Reverse behaviour and critical state of sand with small amount of fines. In Proceedings of the 16th International Conference on Soil Mechanics and Geotechni- cal Engineering (16ICSMGE), Osaka, Japan, Millpress Science Publishers, Rotterdam, the Netherlands. 2: 475-478.

[60] ASTM D7928. Standard Test Method for Particle-Size Distribution (Gradation) of Fine-Grained Soils Using the Sedimentation (Hydrometer) Analysis, American Society for Testing and Materials.

[61] ASTM D4318. Standard Test Methods for Liquid Limit, Plastic Limit, and Plasticity Index of Soils, American Society for Testing and Materials.

[62] Bjerrum L., Kringstad S., Kummeneje D. 1961. The shear strength of a fine sand. In: Proceedings of 5th International Conference on Soil Mechanics and Foundation Engineering, Paris, 1: 29-37.

[63] Leroueil S., Vaughan P.R. 1990. The general and congruent effects of structure in natural soils and weak rocks, Géotechnique, 40 (3): 467-88.

[64] Kramer S.L., Seed H.B. 1988. Initiation of soil liquefaction under static loading conditions, Journal of Geotechnical Engineering, 114 (4): 412-430.

[65] Konrad J.M. 1990. Minimum Undrained Strength Versus Steady-State Strength of Sands. Journal of Geotechnical Engi- neering, 116 (6): 948-963.

[66] Pitman T. D., Robertson P.K., Sego D.C.1994. Influence of Fines on the Collapse of Loose Sands. Canadian Geotechnical Journal, 31 (5): 728-739.

[67] Frost J.D., Park J.Y. 2003. A Critical Assessment of the Moist Tamping Technique. Geotech. Test. J., 26 (1): 57-70.

[68] Rahman M.M., Lo S., Gnanendran C.T. 2008. On equivalent granular void ratio and steady state behaviour of loose sand with fines. Canadian Geotechnical Journal, 45 (10): 1439-1456.

[69] Wanatowski D., Chu J. 2008. Effect of Specimen Preparation Method on the Stress-Strain Behavior of Sand in Plane-Strain Compression Tests. Geotechnical Testing Journal, 31 (4): 308320.

[70] Sadrekarimi A., Olson S.M. 2012. Effect Effect of sample-preparation method on critical-state behavior of sands. Geotechnical Testing Journal, 35 (4): 1-15. 
[71] Ladd R.S. 1978. Preparing test specimens using under compaction, Geotechnical Testing Journal, ASTM, 1 (1): 16-23.

[72] Belkhatir M., Arab A., Missoum H., Della N., Schanz T. 2011. Laboratory study on the liquefaction resistance of sand-silt mixtures: effect of grading characteristics. Granular Matter, 13: 599-609.

[73] Cherif Taiba A., Belkhatir M., Kadri A., Mahmoudi Y., Schanz T. 2016. Insight into the effect of granulometric characteristics on the static liquefaction susceptibility of silty sand soils. Geotechnical and Geological Engineering, 34 (1): 367-382.

[74] Della A., Arab M., Belkhatir M. 2011. Effect of confining pressure and depositional method on the undrained shearing response of medium dense sand. Journal of Iberian Geology, 37 (1): 37 44.

[75] Benahmed N., Nguyen T.K., Hicher P.Y., Nicolas M. 2014. An experimental investigation into the effects of low plastic fines content on the behaviour of sand / silt mixtures. European Journal of Environmental and Civil Engineering. 37-41.

[76] Belhouari F., Bendani K., Missoum H., Derkaoui M. 2015. Undrained static response of loose and medium dense silty sand of Mostaganem (Northern Algeria). Arab. J. Sci. Eng., 40: 13271342.

[77] Mahmoudi Y., Cherif Taiba A., Belkhatir M., Schanz T. 2016. Experimental Investigation on Undrained Shear Behavior of Overconsolidated Sand-silt Mixtures: Effect of Sample Reconstitution. Geotechnical Testing Journal, 39 (3): 515-523.

[78] Karim M.E., Alam J. 2017. Effect of nonplastic silt content on undrained shear strength of sandsilt mixtures. Int J Geo-Engineering, 1-26. 